\title{
The Stress in the Working Environment: A General Point of View of the Effects of Stress on the Productivity of Nurses
}

\author{
Violeta Sadiku(Alterziu) \\ Lecturer at the Depertament of Psychology, Faculty of Educational Sciences \\ University of Elbasan "A.Xhuvani"
}

\begin{abstract}
The main focus of this study is the qualitative analysis of the phenomenon of stress and its influence on the productivity in the working environment. In order to create a clear point of view in the stress-productivity ratio, this study has been channeled in the profession of nurses. For this reason there were selected 8 nurses from the General Hospital in the city of Elbasan, from which 7 are females and 1 is a male. Every member underwent a structured interview, which contains 15 claims. From the analysis of the results it was concluded that the stress has a wide range of spreading and a considerable amount of influence among nurses and their productivity. Furthermore, there were identified some factors and sources of stress such as: the condition of the patients, the lack of working tools and medicaments, people's irresponsibility, the lack of respect toward the hospital's rules, misunderstandings, the work overload and the relationship with the colleagues. Towards the end of the study there are offered some recommendations for the stress management in the working environment, based on the elements which were evidenced from the data analysis.
\end{abstract}

Keywords: Stress, Productivity, service quality, working environment.

\section{Introduction}

Many studies have considered stress as the century's disease, which is constantly 'corroding' society and its individuals. Nobody is immune to stress because people feel it in one way or the other. The word 'stress' has different meanings for different people. Some people define stress as an event or situation which causes the feeling of tension, pressure or negative emotions such as anxiety and anger. Other people see stress as a reaction toward negative and unpleasant situations; this response includes both emotional and physiological changes. The stress affects every aspect of life including the familiar, social and working environment. If we focus on the working environment the stress affects employees not only from the emotional and physiological point of view, but also it influences their productivity and the quality of service. There are many factors which influence a person to be considered as being productive, especially in the working environment. Being productive means to be motivated toward the work done, Hall, L. M (2005). Productivity, theoretically speaking, is a measurement or calculus between the input and the result. The input is the amount of time and work invested whereas the result is the final product. If the results are equivalent with the input the employee is considered to be productive. The stress takes a major deal of importance when it is found in institutions such as hospitals, because the work itself here is of great importance and responsibility.

However, which is the ratio between stress and productivity? Different studies show that the more employees are affected by stress the less productive they are at work. 
Even though it is clear that the stress is a real problem for the category of nurses not many enquiries have been made toward this problem. Based on the knowledge and information attained by studies this issue was not realized before in the Albanian context. This study was decided to be conducted due to the importance, weight and extension of this topic. The validity of this research does not limit only among nurses and the hospitals but also for patients, who are the beneficiary of the health service. This study has a qualitative design where there were sampled 8 nurses of the General Hospital in the city of Elbasan. The results showed that the stress has a wide range of spreading in the work of nurses and a considerable amount of influence among nurses and their productivity.

\section{Research Questions}

How much is the phenomenon of stress spread among nurses?

Which are some of the main sources of stress?

Does stress indicate on nurses' productivity?

\section{Objectives}

80 To investigate the ratio of the variables stress-productivity;

80 To analyze the extension and sources of stress's dispersion;

\&o To find out if stress influences nurses' productivity;

80 To offer recommendations based of the obtained results;

\section{Purpose of the study}

The purpose of this study is to investigate stress and its influence on nurses' productivity. Consequently, in order to fulfill this main aim, it was given a specific importance to the sources of stress and its effects on productivity.

\section{Literature Review}

\section{The stress among nurses}

The actual usage of the term 'stress' comes from Selye, by defining it as a 'non-specific response of the organism for any demand made to it', even though later he accepted that there is not a definition which can entirely describe a qualitative phenomenon such as stress (Selye, 1976). This difficulty continues with different definitions, where the stress is defined as the effect rather than the actual cause. Baum (1990) and Derogatis (1987) describe stress towards an unpleasant emotional experience, or the feeling of pressure influenced by the personality of a person, by the environment or by any the emotional reaction. It has been wildly accepted now that the stress includes discomfort and pressure, even thought Llazar and Folkman (1984) point out that this is highly variable and subjective. The work of nurses was frequently described by many scholars as a complex profession, as their role does not limit only to giving health services, but the role of nurses has a wide extension on other aspects. Furthermore scholars value the weight and importance of this profession, therefore this category of employees is considered among the most exposed category toward experiencing stress in the working environment.

\section{But which are the consequences of stress?}

The stress means a series of biochemical changes which happen and strongly influence every cell in our body. The stress begins within our body, we judge something as stressful though the cerebral cortex which gives the alarm, the messages to the hypothalamus (Baum, A.1990). The stress is accompanied by a series of physiological reactions such as:

1. Increase in the amount of sugar, fats and proteins in our blood; 
2. The saliva dries up, breathing becomes more rapid;

3. The heart beats too fast, the blood pressure increases;

4. The blood vessels in the skin and in the digestive system solidify;

5. The sweating grows;

6. The blood vessels on the surface of the body constrict;

7. The endofin eases pain;

8. The brain's activity grows;

Nevertheless, what is more important is that the stress influences extraordinary on our psyche. The effects of stress in our mind are very high, especially when we are performing a task. Due to stress we might suffer:

1. Difficulty in focusing or bewilderment;

2. Decrease of the ability to remember or oblivion;

3. Inability to organize thoughts or narrowing of thinking;

4. Inability to be realistic;

It is understandable that the psycho-physiological impact that stress has on us automatically will affect on our activity and work. Whenever we are under the effects of pressure of stress we:

1. Haste to perform actions;

2. Can conduce neurotic actions;

3. Can display problems of speech;

4. Display hyperactivity or hasty action (panic);

5. Tend to eat, drink alcohol, coffee, tobacco etc;

\section{Productivity among nurses}

Productivity is determines as the final result of the contribution given in a specific organization related to the amount of consumed sources (McNeese-Smith, 1997). It measures the qualitative and quantitative aspects such as the achieving of goals and the achievements at work (Bain, 1982). Productivity is one of the major indicators in the professional development inside any professional group, by including here even the group of nurses. Productivity is a mass of efficiency of the product.

The productivity among nurses is rarely studied as more importance is given to the relation between the performances of the organization or institutions in general and the efficiency of the working groups. What is measured, as a result, is the quality of service attained by patients. (Helmer \& Suver 1988, Sorrentino 1992, Kennerly 1996).

If we make reference to the working environment, productivity is seen as an element which directly affects the profit of a company. When employees are productive they can achieve more in a specific period of time. However, when the employees are not productive they tend to extend the deadlines of project fulfillment, which costs a lot of many to their employers due to the time wasted (Lazarus, R. S. \& Folkman, S. 1984).

The productivity among nurses is very difficult to measure as it is composed by many elements which influence their work and which causes much complication, these elements are: the knowledge of nurse, the leading systems of the institution, the working conditions, the stress etc.

\section{The elements which compose productivity}

The physical capital: Resources made by human such as vehicles, buildings and cars.

The human capital: The labor force that possesses the skills, education and training. 
The technology: The technical means to produce goods and services. This is the most important driver of productivity according to some economists. It includes not only great inventions, but thousands of small innovations. Productivity can be increased with the growth of the physical capital, of the human capital or of the technology (Moody, RC 2004).

\section{The impact of stress on productivity}

Multiple studies have analyzed the ratio or the relation among stress and productivity. As it was previously mentioned the stress can affect any aspect of an individual's life by including especially the working environment. However, why is there the necessity to study the relation stress-productivity? Whenever we talk about stress we automatically take into consideration even the negative psycho-physiological consequences which stress has among us. Certainly the negative consequences of stress can be projected in the working environment, especially in the diminishing of the employee's productivity, which definitely leads to capital loss (Derogatis, L. R. 1987).

What must be taken under inquiry is the fact that if we return to the studies or literatures which have measured the stressproductivity ratio we can observe a variety of stress sources. However, the results of these studies are all summarized in the conclusion that "if stress in the working environment is high it lowers the productivity of employees". To be more concrete in H. Zemberger's study, which was realized in New Zeeland, it was researched on the negative consequences that stress has on productivity. This study was realized on the employees of a company which produced shoes, and 273 employees of this company were sampled in an intentional way. The results of the study evidenced that there existed a great misbalance among the workload and the deadlines which was given to the employees in order to realize their work. It was established that around $78 \%$ or employees that were sampled resulted to be on a higher level of stress above the average, whereas their level of productivity was under the allowed norm. This study is a very good indicator which efficiently signalizes the factors and sources of stress.

\section{Methodology}

80 Design of the study

This study has a qualitative design. This selection was initialized from the main purpose and objectives that this study has; therefore, the qualitative design makes possible their realization. The purpose of this qualitative study is to unravel this occurrence and this phenomenon. Consequently we can offer the main understanding of the topic and its different points of view altogether.

\section{\&o) Target population/ Sampling}

The target population samples for this study are the nurses of the General Hospital in the city of ELbasan. From this target population there were selected in a purposeful way 8 nurses, from which 1 is a male and 7 are female nurses. The manner of sampling which was selected for this study is not that of probability. The sample of this study is a small but homogeneous group, which means that there was preserved equilibrium among the main criteria that the population has.

\section{so Instruments of data gathering}

With the purpose of collecting the appropriate data for the study it was applied a half structured interview for all the sampled nurses. This interview was created by the researcher itself by relying on the previous researches and literature review. This structured interview contains 15 questions related with stress and productivity. The necessary time in order to apply this instrument to each sampled member of the group is about 35 minutes. 


\section{Data analysis}

All the data gathered from the interviews were analyzed in minimal detail in order to give answers to the research questions of this study. The interview is introduced through a question which aims the general description of the work done by nurses. The main purpose of this question is to reach an understanding of the nurse's perception of the work they perform. In general terms the work of a nurse is a beautiful and humane job which offers special satisfactions. Nevertheless, it is simultaneously an exhausting job, filled with stress and anxiety, accompanied by continuous tensions.

However, what is stress for nurses? The answers to this question were diverse. For somebody stress is perceived as anxiety, tiredness and nervousness. For others stress is compared to a 'heavy rock' that we keep with us. It is worth mentioning the fact that there was a common element in the answers given by all the nurses, they answered that the stress was perceived as something normal, a part of their daily routine. When converted in a scale from 1 to 10 the amount of stress at work according to nurses scored an average of 7.

With the aim of investigating around the stress factors the interviewee were asked to enlist some sources which cause stress in the working environment. Based on the frequency of repeated answers given by the interviewee it was discovered that the main sources of stress were: the condition of the patient, the lack of working tools and medicaments, people's irresponsibility (of patient's relatives) the lack of respect toward the hospital's rules, misunderstandings, the work overload and the relationship with the colleagues.

With the intention of creating a clear overview around the topic of stress the nurses were interrogated even on the elements which accompanied stress. According to the data gathered from the interviews during the moment of stress people felt: tiredness, nervousness, anxiety, headache, sweating (especially in the palms of the hands), and uncertainty.

Nurses in a unanimous way responded with a Yes to the following question: 'Do you properly perform your work under stress?' Here are some arguments offered by nurses in support of their answers:

"My job is so important that it does not let me think about myself, the patient and his condition is what matters here, and not the stress that I have."

"I am now accustomed to stress, due to so many years of work, I know very well what I must do and I try my best doing it."

Nevertheless, even if they do not present traces of stress in the working environment, none of the interviewee negated having experienced it. If the level of stress surpasses the 'bearable' limit, it will indisputably affect the work of nurses, their productivity, performance and quality of service that they offer. This fact was confirmed by another part of the interviewee, who offered even concrete cases when they were unable to realize their job as they should have, due to the presence of stress. In the following paragraph there are cited two of the most interesting cases.

"Approximately four years ago I was a nurse at the reanimation pavilion where my younger brother came with emergency. He had suffered an accident with his motorbike and his condition was very serious and critical. When I was able to see him I froze immediately, I couldn't move my fingers and I was stunned. My brother was reduced to pieces and he was transfigured. It was thanks to God's will that apart from my colleagues there was even the primary doctor, and thankfully now my brother is very well. He suffered a lot... however, thank God he was able to survive and not from my help, because if it had been for me I would not have done anything as I was unable. "

"Probably it was the day when the match between Albania and Armenia was held, but I am not certain. The fans were involved in a physical struggle among each other and around 20-30 patients came into the pavilion simultaneously looking for help. The entire pavilion was involved into chaos, as some people came and other went away. We could not understand any more what was happening, and who to attend first." 
As it can be clearly observed, whenever the level of stress rose, in one way or the other; the work of nurses and their productivity was put at risk. Whenever they were asked on 'what did they understood with the term 'being productive', the interviewed nurses have given different answers. A part of the nurses thought that productivity was 'having ability to fulfill their work in the right way'. 'Being productive' in general terms means to be: active, hard-working, versatile, valuable and able to do one's job. This is how one of the interviewee responded to the question.

"We nurses do not produce anything, however we offer just one thing, the service...in order for me to be called productive my patients will receive from me a very, but very good service."

The interviewees were asked to enlist some factors which affect their productivity, with the purpose of investigating the relation stress-productivity and simultaneously in order to give an answer to one of the research questions of this study. Among the main elements mentioned we can cite: lack of working tools and medicaments. This is how the interviewees responded:

"How can a builder build a palate, if he does not have any bricks not mortar? This is the same thing for us, if we do not have the needed tools."

Other factors which influence productivity are: stress, anxiety and nervousness. The majority of the interviewees said that high levels of stress affected their productivity as when they were under stress they were not concentrated at all. Nurses said that if they were under pressure of stress it made it very difficult for them to realize their job as they should have and they were not $100 \%$ productive.

The interview is concluded with two specific questions: "How do nurses handle with stress at work" and "what would nurses change it they had the possibility, in order to be more productive and less under stress." It was notices that all the answers given followed the same pattern, 'I try to act very normal and not disclose myself', 'I keep the stress inside me', 'I try not to think about that very much' etc. Therefore, to put it in other words, the majority of nurses who were interviewed used evasion as a technique for managing stress in the working environment. Regarding the elements they wanted to change to improve their work, and to decrease the level of stress and increase the level of productivity, they are enlisted as sources which cause stress. Concretely, the interviewee expressed the need for satisfying the shortage of medicaments or working tools. However, simultaneously the nurses were conscious that in order to change a part of the stress sources like: patient and relatives' awareness for following the rules of the hospital, the lack of respect/culture on keeping silence, it is needed to work hard to change, because there is the need for mutual collaboration.

In relation with the data given above, we can conclude that stress has a considerable influence on productivity of nurses. The higher the level of stress is the lower the productivity becomes.

\section{Discussion}

The discussion on the results of the study aims to evident the realization of the purpose of this study. The reason of the realization of this study was the investigation of the extension and diffusion of the stress in the work of nurses; to evidence the main factors of stress, and finally to analyze the impact of stress on the productivity of nurses.

Starting from the data gathered and their analysis we can give answer to the research questions raised during this study. Firstly, it was evidenced an average level of stress experienced by nurses in their working environment. Even though stress is considered to be a daily 'accompany' of their job, stress still stays within normal and confronting levels.

Among the main factors the interviewee enlisted a series of stress factors as having more importance, such as: lack of working tools and medicaments, the work overload, the condition of the patient, the relationship with the colleagues and the relatives of the patients. If we go back and analyze concretely the study realized by $\mathrm{H}$. Zemberger in New Zeeland, we can see that it was noticed that the work overload was considered the primary source of stress. In this case the findings of this study are found in the same line of the findings of other studies. However, it is worth mentioning that in the case of nurses, the stress has a great influence, as the job itself has different specifics. 
The lack of stress management and its mismanagement in the work of nurses can lead to severe consequences. From the data analysis it resulted that stress itself affects on nurses' productivity. Even though the influence of stress on productivity is left in moderate levels, still there is the need to take considerable measures for treating and managing it.

In fact the nurses who were included in this study consider stress as highly productive and argument the fact that independently from being under pressure the experience has helped them control and manage stress better in the working environment. The necessity for stress management in the working environment does not only relate with the low productivity of nurses, but even with their work, with the quality of their job, with the low performance, and above all the mismanagement of stress influences on the psycho-physiological health of nurses.

\section{Recommendations}

Based on the results attained in this study we offer some recommendations for the stress management in the work of nurses:

80 It is recommended to develop special training that will help this category of workers, in order to manage the stress in their work. During these trainings there can be offered different methods with the specifics of time and workload management.

80 Taking into consideration the fact that the main sources of stress in the work of nurses were the relations with the patients, to be more precise with the relatives of the patients, it is recommended to develop specific trainings and seminars where nurses will be able to learn new methods of communication. The main aim is the creation of a collaborative relationship between both parties.

80 From the data analysis it was clearly understood that one of the main methods used by nurses to deal with stress is evasion. This technique or method when used continuously loses its efficiency; it ceases to be valid as it can only accumulate stressing situations. Therefore it is recommended that as a way of stress managing in the working environment nurse should use confrontation, they should treat the problem until they reach a resolution.

\&o Furthermore it is recommended the development of positive thinking, the development of physical activities and a healthy diet and eating habits.

80 Finally, it is recommended the publication of this study and its reference to the parties of interests. As it was highlighted in the beginning of this study, the benefits of it are not limited only to nurses, but to all the hospital as an institution and especially for the patients who are beneficiates of the health service.

\section{References}

Baum, A. (1990). Stress, intrusive imagery, and chronic distress. Health Psychology, (653-675).

Derogatis, L. R.(1987). The Derogatis stress profile (DSP): Quantification of psychological stress. Advances in Psychosomatic Medicine, (30-54).

Hall, L. M. (2005). Indicators of nurse staffing and quality nursing Work environments. In L. M. Hall (Ed.), Quality Work environments for nurse and patient safety. Sudbury, MA: Jones and Bartlett.

Holly CM (1993) The ethical quandaries of acute care nursing practice. Journal of Professional Nursing, (110-115).

Kirpal S (2004) Work identities of nurses: between caring and efficiency demands. Career Development International (274304). 
Lazarus, R. S. \& Folkman, S. (1984). Stress, appraisal, and coping. New York: Springer.

Maben J, Adams M, Peccei R, Murrells T, Robert G (2012) 'Poppets and parcels': the links between staff experience of work and acutely ill older peoples' experience of hospital care. International Journal of Older People Nursing, (83-94).

Moody, R. C. (2004) Nurse Productivity Measures for the 21st Century. Health Care Management Review; 29: 2, 98-106.

Selye, H. (1973). The evolution of the stress concept. American Scientist, (692-699).

Selye,H.(1976). Forty years of stress research: Principal remaining problems and misconceptions. Canadian Medical Association Journal, (53-56).

Zemberger, $\mathrm{H},(2009)$. A qualitative analysis of nursing stress: Consequences for performance. American Educational Research Journal, (13-40). 